\title{
Laju Pertumbuhan Harian dan Nisbah Kelamin Lobster Pasir Panulirus homarus di Perairan Liwungan, Pandeglang, Banten
}

\author{
Dyanita Havshyari Putri Andrykusuma*, Sri Redjeki, Ita Riniatsih \\ Departemen IImu Kelautan, Fakultas Perikanan dan IImu Kelautan, Universitas Diponegoro \\ Jl. Prof.H.Soedarto S.H, Tembalang,Semarang, Jawa Tengah 50275 Indonesia \\ ${ }^{*}$ Corresponding author, e-mail: dyanita.dhpa@gmail.com
}

\begin{abstract}
ABSTRAK: Lobster pasir (Panulirus homarus) merupakan salah satu spesies lobster yang memiliki nilai ekonomi tinggi dalam sumber daya perikanan kelautan Indonesia. Penelitian ini bertujuan untuk mengetahui hubungan panjang-berat lobster pasir, dan nisbah kelamin $P$. homarus yang dibudidayakan dalam keramba jaring apung. Penelitian dengan metoda studi korelasional ini dilakukan di Keramba Jaring Apung PT. Royal Samudera Nusantara, Perairan Liwungan, Pandeglang, Banten, dengan sampel lobster sebanyak 93 ekor. Hasil perhitungan Perhitungan hubungan panjang-berat lobster pasir jantan pada keramba 1 yaitu $W=0,0004 L^{2,51}$ dengan nilai $b=$ $2,51(b<3)$, dan lobster betina yaitu $W=0,0034 L^{2,08}$ dengan nilai $b=2,08(b<3)$. Hubungan panjangberat lobster pasir jantan pada keramba 2 yaitu $W=0,0041 \mathrm{~L}^{2,04}$ dengan nilai $b=2,04(b<3)$, dan lobster betina yaitu $W=0,0012 L^{2,28}$ dengan nilai $b=2,28(b<3)$. Sehingga hubungan panjang-berat pada lobster pasir jantan maupun betina pada keramba 1 dan keramba 2 termasuk dalam kategori pola pertumbuhan allometrik negatif, dimana pertumbuhan panjang lebih cepat daripada pertumbuhan berat. Nisbah kelamin lobster pasir ( $P$. homarus) pada keramba 1 sebesar 1:2,31 dan pada keramba 2 sebesar 1:0,92.
\end{abstract}

Kata kunci: Lobster Pasir; Hubungan Panjang-Berat; Nisbah Kelamin.

\section{Study of Morfometry Scalloped Spiny Lobster (Panulirus homarus) Liwungan, Pandeglang, Banten}

ABSTRACT: Scalloped spiny lobster is a species of lobsters that has high economic value in Indonesia's marine fishery resources. This research aimed to examined the morfometry and sex ratio of Scalloped Spiny Lobster (Panulirus homarus) cultivated in floating net cages. This study used morfometry analysis in PT. Royal Samudera Nusantara's Cultivation Place, Liwungan, Pandeglang, Banten. Samples of lobster obtained 93 lobsters. Relationship of length-weight lobster for males in cage 1 was $W=0,0004 L^{2,51}$ with $b=2,51(b<3)$ and for females was $W=0,0034 L^{2,08}$ with $b=2,08$ $(b<3)$, for males in cage 2 was $W=0,0041 L^{2,04}$ with $b=2,04(b<3)$ and for females was $W=$ $0,0012 L^{2,28}$ with $b=2,28(b<3)$. The results of Scalloped Spiny Lobster morfometric for both males and females shows negative allometric, that carapace length growth faster than weight. Sex ratio Scalloped Spiny Lobster in cage 1 was 1:2,31 which shows that sex ratio is in unbalanced condition, and in cage 2 was 1:0,92 which shows that sex ratio is not significantly different and still in equal condition.

Keywords: Scalloped Spiny Lobster; Morfometry; Sex Ratio.

\section{PENDAHULUAN}

Lobster (Panulirus sp.) merupakan komoditas perikanan yang potensial dan bernilai ekonomis penting. Permintaan untuk pasar domestik dan eksport terus meningkat (Pratiwi, 2018). Lobster diekspor ke Hongkong, Jepang, Tiongkok, Taiwan, dan beberapa negara di Eropa (Nurcholis et al., 2018). Lobster (Palinuridae) umumnya dikonsumsi oleh penggemar seafood. Indonesia memiliki enam jenis lobster, yaitu Lobster Pasir ( $P$. homarus), Lobster Mutiara ( $P$. ornatus), Lobster Batik $(P$. longipes), Lobster Bambu ( $P$. versicolor), Lobster Lumpur ( $P$. polyphagus), dan Lobster Batu ( $P$. penicillatus). Namun jenis lobster yang dominan di perairan Indonesia hanya terdapat empat jenis yaitu Lobster Batik, Lobster Mutiara, Lobster Pasir, dan Lobster Hijau (Setyanto et al., 2018). 
Lobster pasir banyak dibudidayakan oleh masyarakat dikarenakan benih yang mudah didapatkan, dan banyak ditemui di daerah perairan dekat pantai. $P$. homarus ini diperbolehkan untuk budidaya dengan ukuran benih mulai $50 \mathrm{gram}$, dan dapat dipanen setelah berat lobster mencapai 120 gram hingga 150 gram (Zairion et al., 2017). Lobster pasir ( $P$. homarus) termasuk ke dalam kelompok lobster berduri atau disebut juga dengan spiny lobster. Jenis kelamin lobster pasir dapat dilihat dari bentuk dan letak gonadophore serta jumlah lembar pleopod (Sukamto et al., 2017).

Habitat lobster pada umumnya adalah di perairan pantai yang berbatu atau terumbu karang. Terumbu karang ini berguna sebagai pelindung dari ombak, tempat bersembunyi dari predator, dan sebagai daerah pencari makan (Setyanto et al., 2018). Kelimpahan lobster pada suatu perairan ditentukan oleh faktor biotik (seperti pola siklus hidup, penyebaran, dan toleransi terhadap faktor lingkungan), serta faktor abiotik seperti faktor fisika dan kimia perairan, tipe substrat, dan ketersediaan makanan (Wandira et al., 2020). Kondisi perairan yang optimal untuk kehidupan lobster adalah pada salinitas kisaran 25 sampai $35 \mathrm{ppt}$, suhu kisaran $27^{\circ} \mathrm{C}$ sampai $31^{\circ} \mathrm{C}$, pH kisaran 7,5 sampai 8,5, dan nilai oksigen terlarut dalam suatu perairan kisaran $5 \mathrm{mg} / \mathrm{l} \mathrm{sampai} 7 \mathrm{mg} / \mathrm{l}$ (Kordi, 2017).

Penelitian ini bertujuan untuk mengetahui hubungan panjang-berat lobster pasir ( $P$. homarus) di PT. Royal Samudera Nusantara, Perairan Liwungan, Pandeglang, Banten. Dan mengetahui nisbah kelamin lobster pasir ( $P$. homarus) di PT. Royal Samudera Nusantara, Perairan Liwungan, Pandeglang, Banten.

\section{MATERI DAN METODE}

Penelitian ini dilaksanakan pada bulan September 2020 di PT. Royal Samudera Nusantara, Perairan Liwungan, Pandeglang, Banten. Sampel lobster didapatkan dari lobster yang dipelihara pada karamba jaring apung (KJA), sebanyak 93 ekor lobsterMateri penelitian meliputi pengambilan sampel lobster dan pengukuran panjang karapas dan berat lobster. Panjang karapas lobster diukur dengan menggunakan meteran jahit (dengan ketelitian $1 \mathrm{~cm}$ ). berat tubuh lobster diukur dengan menggunakan timbangan digital (dengan ketelitian $1 \mathrm{gram}$ ). Sampel lobster diambil dari lobster yang dipelihara dalam karamba jaring apung sebanyak lobster yang tersedia di masing-masing karamba jarring apung.

Metode yang digunakan dalam penelitian ini adalah metode penelitian studi korelasional. Pengumpulan data primer dilakukan secara langsung dengan mengambil sampel lobster dari 2 Keramba Jaring Apung dengan ukuran $4 \times 4 \mathrm{~m}^{2}$. Hubungan panjang-berat lobster dianalisa dengan menggunakan Software Microsoft Excel, dengan menginput data panjang karapas dan berat lobster. Metode analisa data yang digunakan adalah analisa deskriptif menggunakan tabulasi dan grafik. Hubungan panjang-berat dianalisa menggunakan persamaan (Rahman et al., 2018). Kriteria pola pertumbuhan berdasarkan nilai $b$, disajikan pada Tabel 1. Laju pertumbuhan lobster harian dihitung berdasarkan persamaan Ridwanudin et al. (2018):

\section{HASIL DAN PEMBAHASAN}

Gambar 1a. menunjukkan hubungan panjang-berat lobster pasir ( $P$. homarus) jantan pada keramba $1\left(y=0,0004 x^{2,5144}\right)$ mempunyai nilai $a=0,0004$ dan nilai $b=2,5144$. Hasil tersebut dapat diartikan bahwa lobster pasir ( $P$. homarus) jantan mempunyai sifat allometrik negatif $(\mathrm{b}<3)$, yaitu keadaan dimana pertambahan panjang lebih cepat daripada petambahan berat. Dengan nilai $R^{2}=$ 0,8071 , memiliki nilai korelasi (p) sebesar 0,90 dimana hubungan panjang karapas dan berat lobster pasir jantan di karamba 1 sangat erat.

Tabel 1. Kriteria pertumbuhan berdasarkan nilai b (Rahman et al., 2018)

\begin{tabular}{ccc}
\hline Nilai $b$ & Pola Pertumbuhan & Keterangan \\
\hline$b=3$ & Isometrik & Pertumbuhan panjang sama dengan pertumbuhan berat \\
$b>3$ & Allometrik Positif & Pertumbuhan berat lebih cepat dari pertumbuhan panjang \\
$b<3$ & Allometrik Negatif & Pertumbuhan panjang lebih cepat dari pertumbuhan berat \\
\hline
\end{tabular}


Gambar 1b. menunjukkan bahwa hubungan panjang-berat lobster pasir ( $P$. homarus) betina pada keramba $1\left(y=0,0034 x^{2,0774}\right)$ mempunyai nilai $a=0,0034$ dan nilai $b=2,0774$. Hasil tersebut dapat diartikan bahwa lobster pasir ( $P$. homarus) jantan mempunyai sifat allometrik negatif $(\mathrm{b}<3)$, yaitu keadaan dimana pertambahan panjang lebih cepat daripada petambahan berat. Dengan nilai $R^{2}=0,5529$, memiliki nilai korelasi sebesar 0,74.

Gambar 1c. menunjukkan bahwa hubungan panjang-berat lobster pasir ( $P$. homarus) jantan pada keramba $2\left(y=0,0041 x^{2,0447}\right)$ mempunyai nilai $a=0,0041$ dan nilai $b=2,0447$. Hasil tersebut dapat diartikan bahwa lobster pasir ( $P$. homarus) jantan mempunyai sifat allometrik negatif $(\mathrm{b}<3)$, yaitu keadaan dimana pertambahan panjang lebih cepat daripada petambahan berat. Dengan nilai $R^{2}=0,6606$, memiliki nilai korelasi sebesar 0,81 .

Gambar 1d. menunjukkan bahwa hubungan panjang-berat lobster pasir ( $P$. homarus) betina pada keramba $2\left(y=0,0012 x^{2,2794}\right)$ mempunyai nilai $a=0,0012$ dan nilai $b=2,2794$. Hasil tersebut dapat diartikan bahwa lobster pasir ( $P$. homarus) jantan mempunyai sifat allometrik negatif $(\mathrm{b}<3)$, yaitu keadaan dimana pertambahan panjang lebih cepat daripada petambahan berat. Dengan nilai $\mathrm{R}^{2}=0,67$, memiliki nilai korelasi sebesar 0,82 .

Hasil penelitian ini memiliki hasil yang sama dengan penelitian yang dilakukan oleh Karisma et al. (2017) di Pantai Simeulue Aceh, yaitu pola pertumbuhan lobster memiliki sifat allometrik negatif. Kesamaan pola pertumbuhan tersebut diduga dikarenakan karakteristik perairan yang sama dalam ketersediaan makanan dan habitat yang sesuai. Hal tersebut didukung oleh pernyataan Fauzi et al. (2013), bahwa model pertumbuhan individual bergantung pada ketersediaan pakan dan karakteristik perairan. Jika terjadi kesamaan pola pertumbuhan, diduga terdapat kesamaan faktor penunjang pertumbuhan tersebut.

Menurut Muttaqin et al. (2016), hasil analisa regresi pada grafik hubungan panjang-berat memiliki arti bahwa pertambahan berat lobster memiliki keeratan dengan pertambahan panjangnya. Hasil regresi hubungan panjang-berat penelitian ini bernilai positif dan mendekati satu, bahwa terdapat hubungan yang kuat antara variabel panjang karapas dengan berat lobster. Sesuai dengan penelitian yang dilakukan oleh Nurhayati et al. (2016), nilai $\mathrm{R}^{2}$ yang diperoleh mendekati +1 menunjukkan bahwa hubungan koefisien korelasi antara variabel panjang dan berat memiliki hubungan yang kuat. Berdasarkan Muchlisin (2016), perbandingan pola pertumbuhan prediksi dan observasi suatu organisme dapat dijelaskan dengan nilai koefiensi determinasi $\left(R^{2}\right)$. Hasil perhitungan rata-rata laju pertumbuhan harian lobster pasir dapat dilihat pada Tabel 2.

Hasil perhitungan laju pertumbuhan lobster pasir jantan pada keramba 1 sebesar $0,66 \%$ /hari dan keramba 2 sebesar 0,51\%/hari. Hasil tersebut menunjukkan bahwa laju pertumbuhan lobster jantan pada keramba 1 lebih tinggi dibandingkan lobster jantan pada keramba 2. Begitu pula dengan hasil perhitungan laju pertumbuhan lobster pasir betina pada keramba 1 sebesar $0,52 \% /$ hari dan keramba 2 sebesar 0,49\%/hari, menunjukkan bahwa laju pertumbuhan lobster betina pada keramba 1 lebih tinggi dibandingkan lobster betina pada keramba 2.

Laju pertumbuhan lobster pasir penelitian ini sesuai dengan penelitian Hargiyanto et al. (2013) bahwa pertumbuhan berat lobster pasir sebesar $0,45 \%$ /hari pada tangki pembesaran dan $0,5 \% /$ hari di laut. Kesamaan laju pertumbuhan yang diperoleh diduga terjadi karena adanya karakteristik perairan yang sama dalam ketersediaan makanan dan habitat yang sesuai. Ketersediaan bahan makanan yang cukup dapat mempercepat laju pertumbuhan lobster.

Tabel 2. Laju Pertumbuhan Harian Lobster Pasir (\%/hari)

\begin{tabular}{ccc}
\hline Keramba & Jenis Kelamin & Laju Pertumbuhan Harian \\
\hline \multirow{2}{*}{ Keramba 1 } & Jantan & 0,66 \\
& Betina & 0,52 \\
Keramba 2 & Jantan & 0,51 \\
& Betina & 0,49 \\
\hline
\end{tabular}




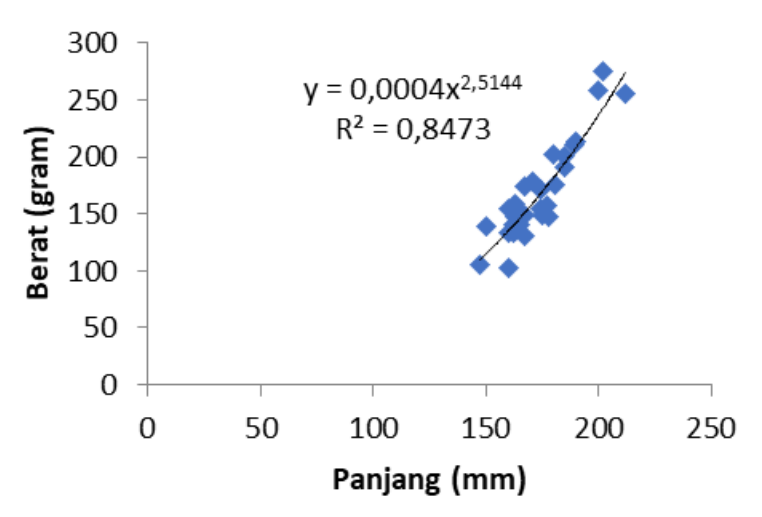

a.

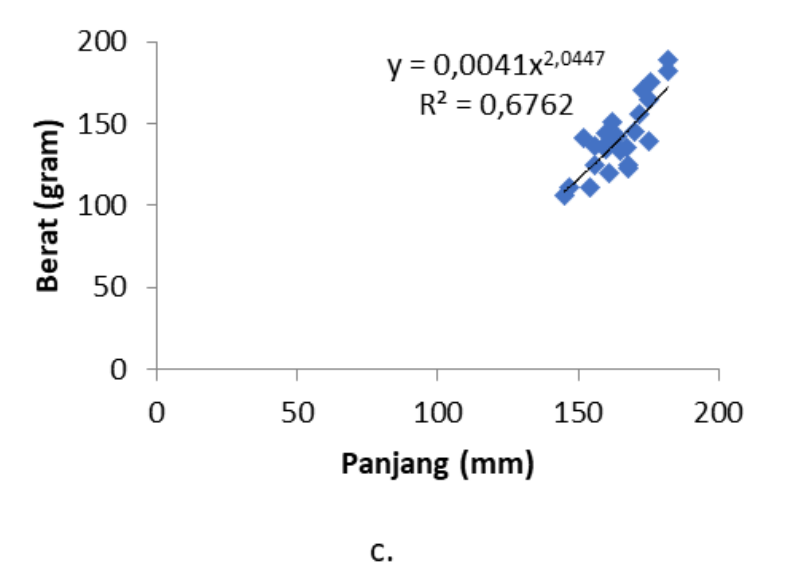

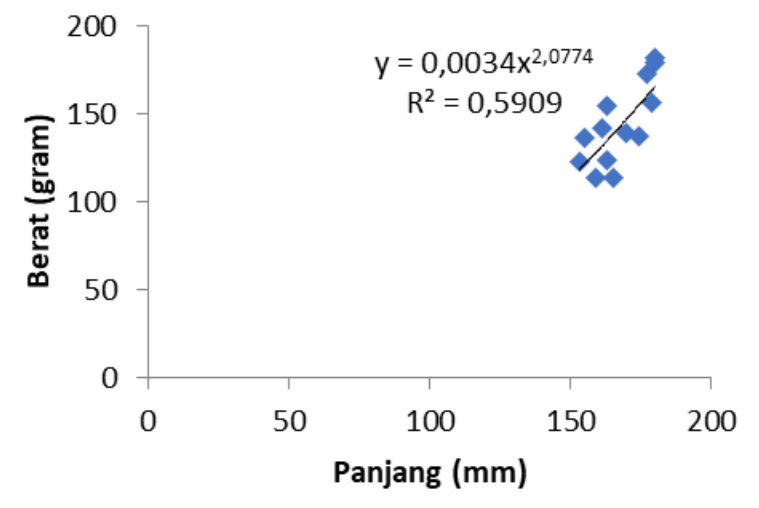

b.

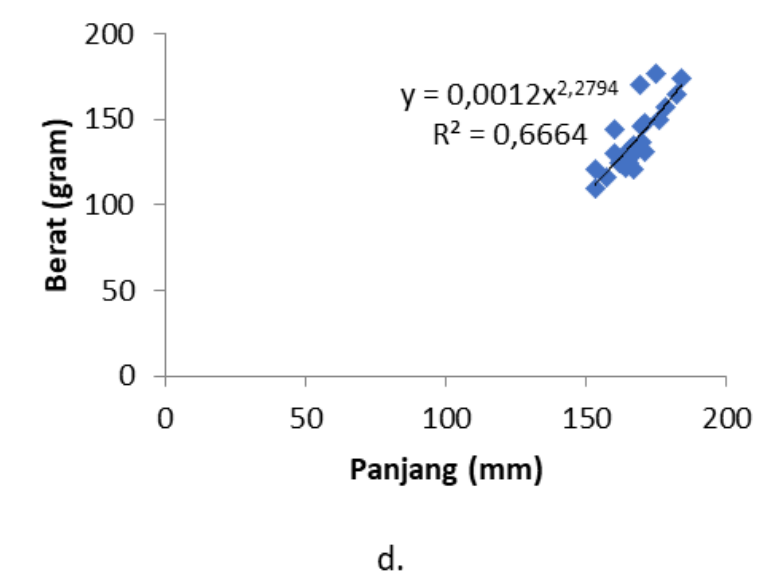

Gambar 1. Hubungan Panjang-Berat Lobster Pasir ( $P$. homarus) pada Keramba 1 dan Keramba 2: (a) Lobster Pasir Jantan pada Keramba 1, (b) Lobster Pasir Betina pada Keramba 1, (c) Lobster Pasir Jantan pada Keramba 2, dan (d) Lobster Pasir Betina pada Keramba 2. Keterangan: Sumbu $\mathrm{X}=$ Panjang Lobster $(\mathrm{mm})$ dan Sumbu $\mathrm{Y}=$ Berat Lobster (gram)

\section{Nisbah Kelamin}

Jumlah sampel lobster pasir ( $P$. homarus) yang diperoleh pada saat pengambilan data adalah sebanyak 93 ekor lobster pasir. Jumlah sampel lobster pasir ( $P$. homarus) pada keramba 1 sebanyak 43 ekor lobster pasir, dengan jumlah lobster jantan 30 ekor dan lobster betina 13 ekor. Sedangkan jumlah sampel lobster pasir ( $P$. homarus) pada keramba 2 sebanyak 50 ekor lobster pasir, dengan jumlah lobster jantan 24 ekor dan lobster betina 26 ekor. Data hasil pengamatan nisbah kelamin lobster pasir ( $P$. homarus) keramba 1 dan 2 disajikan pada Tabel 3.

Tabel 3. Data Nisbah Kelamin Lobster Pasir pada Keramba 1

\begin{tabular}{cccc}
\hline Karamba & Jenis Kelamin & Jumlah $(\mathrm{n})$ & Nisbah Kelamin \\
\hline \multirow{2}{*}{1} & Jantan & 30 & 2,31 \\
& Betina & 13 & 1 \\
\hline \multirow{2}{*}{2} & Jantan & 24 & 0,92 \\
& Betina & 26 & 1 \\
\hline
\end{tabular}

Hasil perhitungan nisbah kelamin atau sex-ratio lobster pasir ( $P$. homarus) yang dibudidayakan pada Keramba 1 sebesar 1:2,31. Hasil nisbah kelamin ini menunjukkan bahwa individu jantan dan betina pada keramba 1 dalam keadaan tidak seimbang karena jumlah lobster jantan lebih banyak daripada lobster betina. Rochmadi (2012) menyebutkan bahwa pada keadaan normal, rasio kelamin yang berbeda merupakan suatu strategi reproduksi pada keadaan lingkungan 
tertentu. Kecenderungan individu jantan lebih banyak daripada individu betina merupakan strategi reproduksi dalam pengoptimalan keberhasilan reproduksi pada suatu perairan.

Hasil perhitungan nisbah kelamin atau sex-ratio lobster pasir ( $P$. homarus) yang dibudidayakan pada Keramba 2 sebesar 1:0,92. Hal ini menunjukkan bahwa nisbah kelamin antara individu jantan dan betina tidak berbeda nyata dan masih dalam keadaan seimbang. Hasil nisbah kelamin menunjukkan perbandingan yang tidak sama, namun relatif seimbang. Keseimbangan perbandingan jumlah individu jantan dan betina memungkinkan kelestarian suatu populasi dapat dipertahankan (Yusuf et al., 2019).

Menurut hasil peneltian yang telah dilakukan oleh Junaidi et al. (2010), analisa nisbah kelamin $P$. homarus diperoleh perbandingan 1:1,74 dengan dugaan bahwa nisbah kelamin antara individu jantan dan betina dalam keadaan seimbang. Hal ini juga sesuai dengan penelitian yang telah dilakukan oleh Karisma et al (2017), bahwa keseimbangan perbandingan individu jantan dan betina dipengaruhi oleh tingkah laku seks dalam satu kondisi lingkungan perairan.

\section{KESIMPULAN}

Hubungan panjang-berat lobster pasir Perairan Liwungan, Pandeglang, Banten termasuk dalam kategori pola pertumbuhan allometrik negatif, dimana pertumbuhan panjang lebih cepat daripada pertumbuhan berat. Laju pertumbuhan lobster pasir ( $P$. homarus) pada keramba 1 lebih tinggi dibandingkan dengan lobster pasir ( $P$. homarus) pada keramba 2. Nisbah kelamin lobster pasir ( $P$. homarus) Perairan Liwungan, Pandeglang, Banten pada keramba 1 sebesar 1:2,31 sehingga nisbah kelamin antara individu jantan dan betina tidak seimbang. Dan nisbah kelamin lobster pasir ( $P$. homarus) pada keramba 2 sebesar 1:0,92 sehingga nisbah kelamin antara individu jantan dan betina tidak berbeda nyata dan masih dalam keadaan seimbang.

\section{DAFTAR PUSTAKA}

Fauzi, M., Prasetyo, A.P., Hargiyanto, I.T., Satria, F., \& Utama, A.A., 2013. Hubungan PanjangBerat dan Faktor Kondisi Lobster Batu (Panulirus penicillatus) di Perairan Selatan Gunung Kidul dan Pacitan. Bawal, 5(2):97-102. DOI: 10.15578/bawal.5.2.2013.97-102

Hargiyatno, I.T., Satria, F., Prasetyo, A.P., \& Fauzi, M., 2013. Hubungan Panjang-Berat dan Faktor Kondisi Lobster Pasir (Panulirus homarus) di Perairan Yogyakarta dan Pacitan. Bawal, 5(1): 41 48. DOI: 10.15578/bawal.5.1.2013.41-48

Junaidi, M.,Cokrowati, N. \& Abidin, Z., 2010. Aspek Reproduksi Lobster (Panulirus sp.) di Perairan Teluk Ekas Pulau Lombok. Jurnal Kelautan, 3(1): 29-35. DOI: 10.21107/jk.v3i1.839

Karisma, N., Dewiyanti, I., \& Rizwan. 2017. Hubungan Panjang-Berat dan Faktor Kondisi Lobster (Panulirus sp.) di Perairan Pantai Simeulue Selatan. Jurnal IImiah Mahasiswa Kelautan dan Perikanan Unsyiah, 2(1):175-182.

Kordi, M. G. H. 2017. Farm Bigbook - Budi Daya Komoditas Perikanan Laut Unggulan, Populer, dan Prospektif. Yogyakarta: Lily Publisher. Hal: 535-536.

Muchlisin, Z.A. 2016. Kebiasaan Makanan dan Hubungan Panjang-Berat Ikan Julung-Julung (Dermogenys sp.) di Sungai Alur Hitam Kecamatan Bendahara Kabupaten Aceh Tamiang. Jurnal Ilmiah Mahasiswa Kelautan dan Perikanan Unsyiah, 1(1): 12-24

Muttaqin, Z., Dewiyanti, I., \& Aliza, I. 2016. Kajian Hubungan Panjang Berat dan Faktor Kondisi Ikan Nila (Oreochromis niloticus) dan Ikan Belanak (Mugil cephalus) yang Tertangkap di Sungai Matang Guru, Kecamatan Madat, Kabupaten Aceh Timur. Jurnal Ilmiah Mahasiswa Kelautan dan Perikanan Unsyiah, 1(3): 397-403.

Nurcholis, I., Zairion, \& Mashar, A., 2018. Parameter Dinamika Populasi Lobster Batu (Panulirus penicillatus Olivier, 1791) di Teluk Palabuhanratu, Sukabumi, Jawa Barat. Jurnal Pengelolaan Perikanan Tropis., 2(2):34-44. DOI: 10.29244/jppt.v2i2.26319

Nurhayati, Fauziyah, \& Bernas, S.M., 2016. Hubungan Panjang-Berat dan Pola Pertumbuhan Ikan di Muara Sungai Musi Kabupaten Banyuasin Sumater Selatan. Maspari Journal, 8(2):111-118

Pratiwi, R. 2018. Keanekaragaman dan Potensi Lobster (Malacostraca: Palinuridae) di Pantai Pameungpeuk, Garut Selatan, Jawa Barat. Biostera, 35(1):10-22. DOI: 10.20884/1.mib.2018. 35.1 .524 
Rahman, A., Hedianto, D.A., \& Wijaya, D., 2018. Sebaran Ukuran dan Faktor Kondisi Lobster Pasir (Panulirus homarus Linnaeus 1758) di Pananjung Pangandaran. Widyariset, 4(2): 205-211. DOI: 10.14203/widyariset.4.2.2018.205-211

Ridwanudin, A., Fahmi, V., \& Pratama, I.S., 2018. Pertumbuhan Lobster Pasir Panulirus homarus dengan Pemberian Pakan Moist. Oseanologi dan Limnologi di Indonesia, 3(2):95-103. DOI: 10.14203/oldi.2018.v3i2.165

Rochmadi, Omar, S.B.A., \& Tandipayuk, L.S., 2012. Nisbah Kelamin dan Ukuran Pertama Kali Matang Gonad Kerang Lumpur Anodontia edentula, Linnaeus 1758 di Pulau Tobea, Kecamatan Napabalano, Kabupaten Muna. Jurnal IImiah Agribisnis dan Perikanan, 5(2):25-32. DOI: 10.29239/j.agrikan.5.2.25-32

Setyanto, A., Rachman, N.A., \& Yulianto. E.S. 2018. Distribusi dan Komposisi Spesies Lobster yang Tertangkap di Perairan Laut Jawa Timur, Indonesia. Jurnal Perikanan Universitas Gadjah Mada, 20(2):49-55. DOI: 10.22146/jfs.36151

Sukamto, Muryanto, T., \& Kusiani, H., 2017. Teknik Identifikasi Jenis Kelamin Lobster Berbasis Ciri-Ciri Morfologi. Buletin Teknik Litkayasa, 15(2):99-102. DOI: 10.15578/btl.15.2.2017.99-102

Wandira, A., Ramli, \& Halili, M., 2020. Jenis dan Kelimpahan Benih Lobster (Panulirus spp.) Berdasarkan Kedalaman di Perairan Desa Ranooha Raya, Kecamatan Moramo, Kabupaten Konawe Selatan. Sapa Laut, 5(2):163-172. DOI: 10.33772/jsl.v5i2.12171

Wiadnyana, N.N., Triharyuni, S., \& Prihatiningsih. 2018. Nisbah Kelamin, Ukuran Pertama Kali Tertangkap, dan Catch Per-Unit Effort Dua Jenis Lobster Kipas (Scyllaridae) di Perairan Kupang dan Sekitarnya. Jurnal Penelitian Perikanan Indonesia, 25(1):27-34. DOI: 10.15578/jppi.25.1.2019.27-34

Yusuf, H.N., Noegroho, N., \& Suman, A. 2019. Pertumbuhan Lobster Batu (Panulirus penicillatus Olivier, 1791) di Perairan Simeulue, Barat Sumatera. Jurnal Kelautan dan Perikanan Terapan, 2(2):101-111. DOI: 10.15578/jkpt.v2i2.7390

Zairion, Islamiati, N., Wardiatno, Y., Mashar, A., Wahyudin, R.A., \& Hakim, A.A., 2017. Dinamika Populasi Lobster Pasir (Panulirus homarus Linnaeus, 1758) di Perairan Palabuhanratu, Jawa Barat. Jurnal Penelitian Perikanan Indonesia., 23(3):215-226. DOI: 10.15578/jppi.23.3.2017. 215-226 